\title{
CORRESPONDENCE
}

\section{Predictive factors for death in paediatric acute respiratory failure}

\section{To the Editor:}

In a recent contribution to The Journal, EwIG et al [1] found that a high heart rate $\left(>90\right.$ beats $\left.\cdot \mathrm{min}^{-2}\right)$ and a low mean diastolic and systolic blood pressure were most closely associated with a fatal outcome in patients with community-acquired pneumonia. This is a surprising result, as general opinion would think of respiratory and ventilatory parameters and sophisticated indices and ratios based upon these data as most valuable indicators of survival in severe acute respiratory disease. We would strongly suggest that this is a universal finding in acute respiratory failure and not only in community-acquired pneumonia patients.

In an analysis of 69 paediatric patients with acute respiratory distress syndome (ARDS) arterial oxygen tension/fractional inspiratory oxygen $\left(\mathrm{Pa}_{\mathrm{a}} \mathrm{O}_{2} / F_{\mathrm{I}}, \mathrm{O}_{2}\right)$ ratio $\left.<150\right)$ we studied the predictive power of the oygenation index $\left(\mathrm{Pa}, \mathrm{O}_{2} / F_{1}, \mathrm{O}_{2}\right)$, respiratory index $\left(\mathrm{RI}=\mathrm{A}-\mathrm{aD}, \mathrm{O}_{2}-\mathrm{Pa}, \mathrm{O}_{2} / \mathrm{Pa}, \mathrm{O}_{2}\right)$, $\mathrm{Pa}_{\mathrm{a}} \mathrm{O}_{2}$ alone, a paediatric respiratory severity index (RSI $=$ mean airway pressure $\left.\times \mathrm{A}-\mathrm{aD}, \mathrm{O}_{2} / \mathrm{Pa}_{\mathrm{a}} \mathrm{O}_{2} \times 100[2]\right)$ and other parameters to predict survival. We could not find any respiratory parameter discriminating between survivors and nonsurvivors of paediatric ARDS [3, 4].

However, the blood pressure and heart rate in nonsurvivors at admission to the Intensive Care Unit (ICU) was significantly lower than in survivors. Coincidentally, nonsurvivors at admission had more organ dysfunction, i.e. a higher degree of multiorgan dysfunction syndrome (MODS) [5].

As only 8 of our 69 ARDS patients had underlying pneumonia, we conclude that haemodynamic parameters and the related degree of MODS are the best indicators of survival in all cases of acute respiratory failure, not only in community-acquired pneumonia. A lower initial heart rate in paediatric ARDS patients could be explained by the different haemodynamic adaptation mechanisms in children, where an increased heart rate is usually the only reasonable adaptative mechanism to increase cardiac output, and a low rather than a high heart rate indicates the collapse of cardiac adaptation [6].

\section{References}

1. Ewig S, Bauer T, Hasper E, Pizzuli L, Kubini R, Lüderitz B. Prognostic analysis and predictive rule for outcome of hospital-treated community-acquired pneumonia. Eur Respir J 1995; 8: 392-397.

2. Zobel G, Kuttnig M, Trop M, Grubbauer HM. A respiratory severity index for children with ARDS. Clin Intens Care 1990; 1: 17-21.

3. Möller JC, Raszynski A, Vardag A, Richter A, Tegtmeyer FK. The usefulness of mortality predicting indices in pediatric ARDS. Eur Respir J 1991; 4: 205S.

4. Möller JC, Raszynski A, Richter A, Tegtmeyer FK. The prognostic value of respiratory indices in pediatric ARDS. Anaesthetsist 1992; 41: 399-402.

5. Möller JC, Raszynski A, Tegtmeyer FK, Gortner L. Akutes respiratorisches (ARDS) und Multiorganversagen (MODS) im Kindesalter. Monatsschr Kinderheilkd 1994; 142: S36.

6. Royall JA, Levin DL. Adult respiratory distress syndrome in pediatric patients. I. Clinical aspects, pathophysiology, pathology, and mechanism of lung injury. $J$ Pediatr 1988; 112: 169-180.

\section{J.C. Möller}

Klinik f. Paediatrie, Der Medizinischen Universitaet, Kshlhorststr. 31-35, D-21538 Luebeck, Germany.

\section{REPLY}

\section{From the authors:}

Lethal outcome in community-acquired pneumonia may result from a variety of conditions, including respiratory failure, septic shock, complications of organ failures and of adverse effects of therapeutic interventions. Moreover, a combination of these conditions may be present in a significant number of cases. Only very large series would be able to adjust the prognostic factors associated with death for all these different end-points. Thus, it appears difficult to assign a parameter found to be associated with lethal outcome to a distinctive underlying pathophysiological basis. Heart rate and blood pressures may well reflect acute respiratory failure but also other pulmonary or systemic complications. Therefore, even if these parameters also had prognostic implications in other severe clinical settings this would not necessarily imply identical underlying conditions.

The clinical and laboratory parameters found to be associated with death from community-acquired pneumonia in previous studies, as well as in our investigation, are of

course unspecific. Moreover, a single parameter is unlikely to be clinically applicable in the individual patient.

The predominant interest of a prognostic analysis from a clinical point of view is to identify a prognostic rule. This rule should add prognostic information to the results of clinical investigation. Therefore, heart rate and systolic blood pressure, as well as the lactate dehydrogenase level, (LDH) may prove to be relevant prognostic factors because they are associated with death at cut-off levels that do not necessarily imply severe respiratory or circulatory failure apparent to clinical judgement. Thus, these parameters are of interest predominantly because of their cut-off levels. It would be interesting whether the prognostic rule identified in our population could also be applied to respiratory failure of any origin.

\section{S. Ewig}

Medizinische Universitätsklinik und Poliklinik Bonn, Innere Medizin/Kardiologie und Pneumologie, Sigmund FreudStr. 25, 53105 Bonn, Germany. 